all the islands remained clouded. The captain did not experience any shower of ashes. The master of the steamer Conrad, which arrived at Batavia on May 24, reports having passed Krakatan on the north side the previous night, and met with heavy rains of ashes, covering the decks, \&c., with about $\mathrm{I} \frac{1}{2}$ inch of ashes. He also had to cut his way through nearly $I \frac{1}{2}$ metres of pumice-stone, which occasioned a delay of almost five hours.

WE have already referred in NATURE to the excellent scientific work being done by the French in the Indo.Chinese peninsula, as evinced by the large number of scientific missions which have been despatched from France to those regions. As a farther example of the pains taken in France to obtain a thorough knowledge of the country in which she seems destined to play so large a part, we may refer to a periodical published by the Government of Saig on, entitled Cochin-chine Française: Excursions et Reconnaissances. The fifteenth part is now before us, and as each part contains about two hundred pages the amount of information accumulated in these volumes is considerable. Speaking broadly, and slightly altering a wellknown Latin maxim, it may be said that nothing relating to the vast territory between the mouths of the Brahmaputra and the Canton river, between the Bay of Beng $l 1$ and the China Sea, is outside the scope of this journal. As a rule the papers are of a highly scholarly and scientific kind. Thus the last number contains the second part of a long and richly illustrated paper on the coins and medals of Annam and French Cochin China, by M. Silvestre, inspector of native affairs in Saigon ; a short history of the Portuguese in Cambodia; an account of the typhoon of last November at Hué, the capital of Annam, with barometrical tables, by the surgeon to the French Legation there; a long paper on the vegetation and forest administration of British Burmah; and finally one of a series of very interesting papers on the customs and popular stiperstitions of the Annamites. The present instalment deals with marriage customs. The efforts of the Colonial Government to sustain and encourage the study of Indo-China does not, however, close with the publication of this excellent journal, for we observe the advertisements of a large number of works relating to that country in the magazine under review. Among these are a weekly journal for the natives, an annual summary of facts relating to Cochin China, vari us maps, medical reports, \&c. Whatever may be thought from other points of view of the action of France in Annam and Tonkin, there can be no doubt that the increase of French power there carries with it a large increase to knowledge, for the Colonial Government of France appears to know how to organise and stimulate research in the countries over which it exercises rule.

THE telegraph has made another step in advance in China. It has had the honour of being mentioned in a memorial to the throne. Li Hung Chang recently mentioned in a report to the Emperor that he received certain information by telegraph. And, more wonderful still, that mysterious and awe-inspiring document, an Imperial decree, written with the vermilion pencil, has actually been despatched by telegraph, for the Viceroy of Canton reports recently in a memorial that a decree had been conveyed to him in this way.

THE German system of privat docenten, or University teaching by outsiders, is to be tried in France. A decree provides that any doctor of letters or sciences, or correspondent or member of the Institute, may apply to the Minister of Education for permission to lecture on his respective subject, the license being renewable annually. The lectures may be public or private, at the professor's option, and the expense falls on him, while he can charge the students what he pleases. The same system is applied to the medical school.
WE lave received the Transactions of the Norfolk and Nornich Naturalists' Society for I882-83. In the first paper, on the scenery of Norfolk, Mr. Horace Woodward gives a history of the geological strata of the county, shows how the scenery was influenced by the action of water and the introduction of various forms of life, and how affected by the artificial changes brought about by man. There is also an interesting paper by Mr. Stevenson on the dusky petrel, and a paper by Mr. Southwell on the bottle-nosert whale and the history of the seal fishery. Mr. Clement Reed's paper on the discovery of Lithoglyphus in the Weybourn Crag is very interesting, from the fact that this freshwater shell is found now in Europe only in the Ianube. Mr. Young gives his observations on the habits of the bearded tit, which birds he had kept in confinement for twelve years. Mr. Bidwell's list of British birds in whose nest the egg of the cuckoo has been found is the most complete yet published. The President contributes part $x$. of the fauna and flora of Norfolk, a list of the marine algæe.

THE exhibition of the Society of Agriculture and Insectology of Paris has just come to an end with a ministerial visit and distribution of prizes at the Palais de l'Industrie. Thousands of visitors have flocked to this hall in order to visit the interesting collection. A special building will be erected for the Society in the Park de Montsouris, and a sum of 32,000 francs has been already voted for this purpose by the city of Paris. A menayerit: of living insects is to be established.

According to the Austrian Monatschrift fiur den Orient the production of tin in the protected state of Perak, in the Malay Peninsula, for the year 1882 was 7000 tons, about equivalent to that of Cornwall. Forty thousand Chinese are employed in the Malacca tin mines.

THE additions to the Zoological Society's Gardens during the past week include a Macaque Monkey (Macacus cynomolgus of) from India, presented by Mr. J. W. Lucking; a White-thruatea Capuchin (Cebus hypoleucus of) from Central America, presented by Mr. F. Hoëy; a Leopard (Felis pardus) from Somali Land, East Africa, presented by Mr. Frederick Holmwood; four Babiroussas (Babirussa alfurus of $\delta$ q $q$ ) from Celebes, presented by Dr. F. H. Bauer, C.M.Z.S.; a Two-spotted Para. doxure (Nandinia binotata b), a Royal Python (Python regius) from West Africa, presented by Dr. D. Hume Hart; two Shortheaded Phalangers (Belideus brevicaps of $q$ ), two Crested Pigeons (Ocyphaps lophotes o $\$$ ), a Modest Grass Finch (Amadina modesta) from Australia, two Bicheno's Finches (Estrelda bichenovii) from Queensland, a Funereal Cockatoo (Calyptorhynchus funereus) from New South Wales, a Saisset's Parra. keet (Cyanorhamphus saisseti) from New Caledonia, a Neu Zealand Parrakeet (Cyanorhamphus nove-zealandic) from New Zealand, presented by Mr. T. H. Bowyer Bower, F.Z.S.; an Australian Cassowary (Casuarius australis) from Australia, presented by Capt. Mann; four Black Guillemots (Uria grylle) from Ireland, presented by Mr. H. Becher; a South American Rat Snake (Spilotes variabilis) from Brazil, presented by Mr. C. A. Craven, C.M.Z.S. ; two Peacock Pheasants (Polyplectron chinquis of of ) from British Burmah, deposited.

\section{WEATHER PROGNOSTICS AND WEATHER TYPES}

THE object of the first paper was to explain the best known popular prognostics by means of the most recent discoveries in metecrological science.

A great advance has been made in meteorology during the last twenty years owing to the introduction of daily synoptic charts of the distribution of atmospheric pressure, temperature,

x Abstract of two papers read before the Meteorological Society: "On Weather Prognostics," by Hon. Ralph Abercomby and W. Marriott; " "in certain Types of Eritish Weather," by Hon. R. Abercromby. (Quarterly Journal of the Meteorological Society, vol. ix. No. 45.) 
wind, rain, \&c. From these it is evident that there is a distinct relation existing between the distribution of pressure and the direction and force of the wind, and temperature and weather generally. A glance at a number of the charts shows that there is nearly always present either an area of low pressure called a cyclone, usually having a circular form, and as a rule moving in an easterly or north-easterly direction; or an area of high pressure, called an anticyclone, also nearly circular in form but almost stationary in position. The wind in all cases also blows nearly parallel with the isobars, having the region of lowest pressure on the left hand. This has given rise to the following simple law propounded by Dr. Buys Ballot for the northern hemisphere,

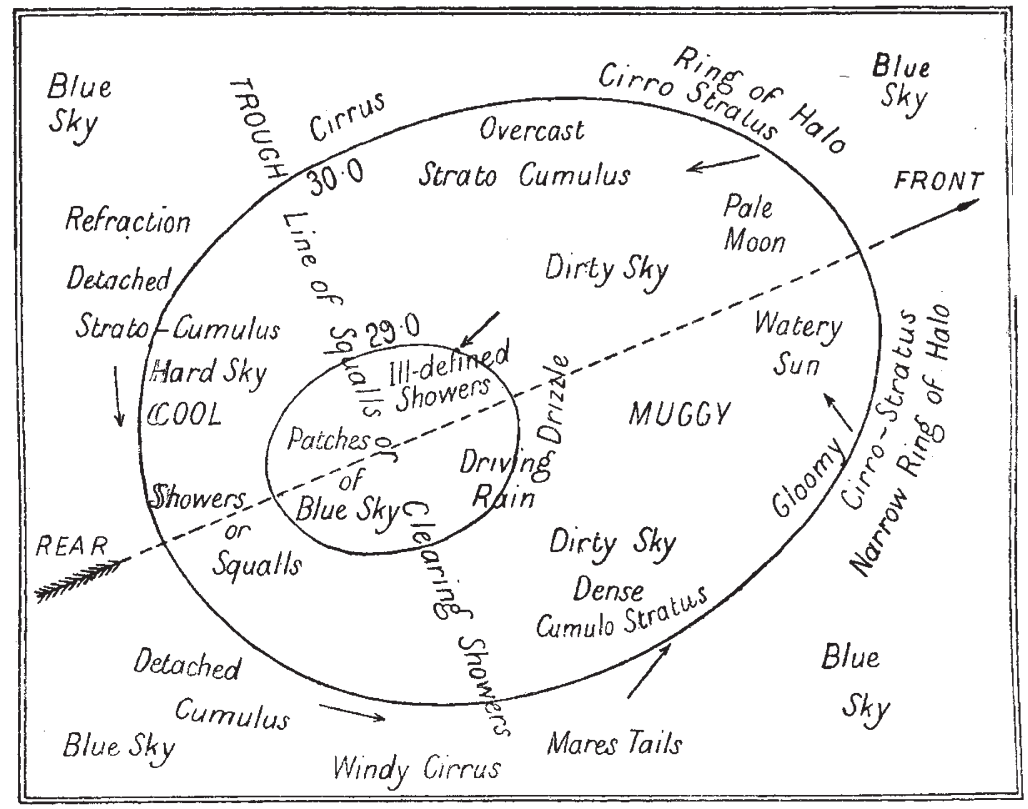

Fig. I.-Cyclore Prognostics.

viz. "Stand with your back to the wind, and the barometer will in the same way as the hands of a watch, but exhibits usually be lower on your left hand than on your right." In cyclones a little outward motion. The velocity of the wind in all cases the wind circulates round the isobars in the opposite way to depends mainly upon the closeness of the isobars; for the closer the which the hands of a watch move, but exbibits usually a little isobars the greater is the difference in pressure, and consequently indraft; while in anticyclones the wind circulates round them the stronger the wind.

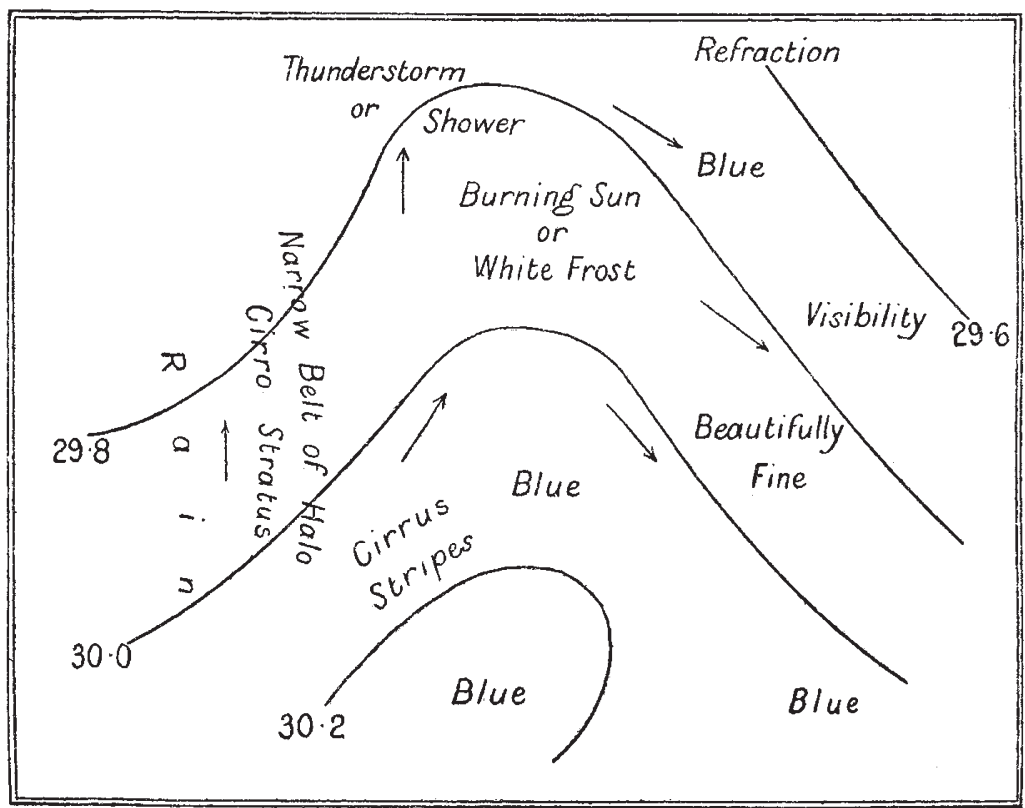

FIG. 2.-Wedge-Shaped Isobar Prognostics.

Since therefore nearly all our weather is of the cyclonic or anti- The method of research actually adopted has been for many cyclonic type, and is entirely dependent upon the form and close- years past to take notes of any good observation of any progness of the isobars, it is by the aid of isobaric charts that the nostic and put them by in a portfolio with the nearest synoptic authors have attempted to explain a number of popular prog- chart available; or preferably with the nearest both before and nostics, and to associate them with certain kinds of weather. after. When a sufficient number had been collected they were 
analysed, and the remarkable result has been arrived at that the $\mid$ areas of rain or blue sky which are mapped out by the isobaric greater number of prognostics are simply descripiive of the lines.

weather and appearance of the sky in the different portions of These charts not only show the success of the prognostic;, but the various shapes of isobars seen on synoptic charts; and that also explain wherein they sometimes fail, by tracing the changes they indicate foul or fair weather just as they precede the shifting of each particular condition of weather. Hitherto the only pro ${ }_{5}$ -

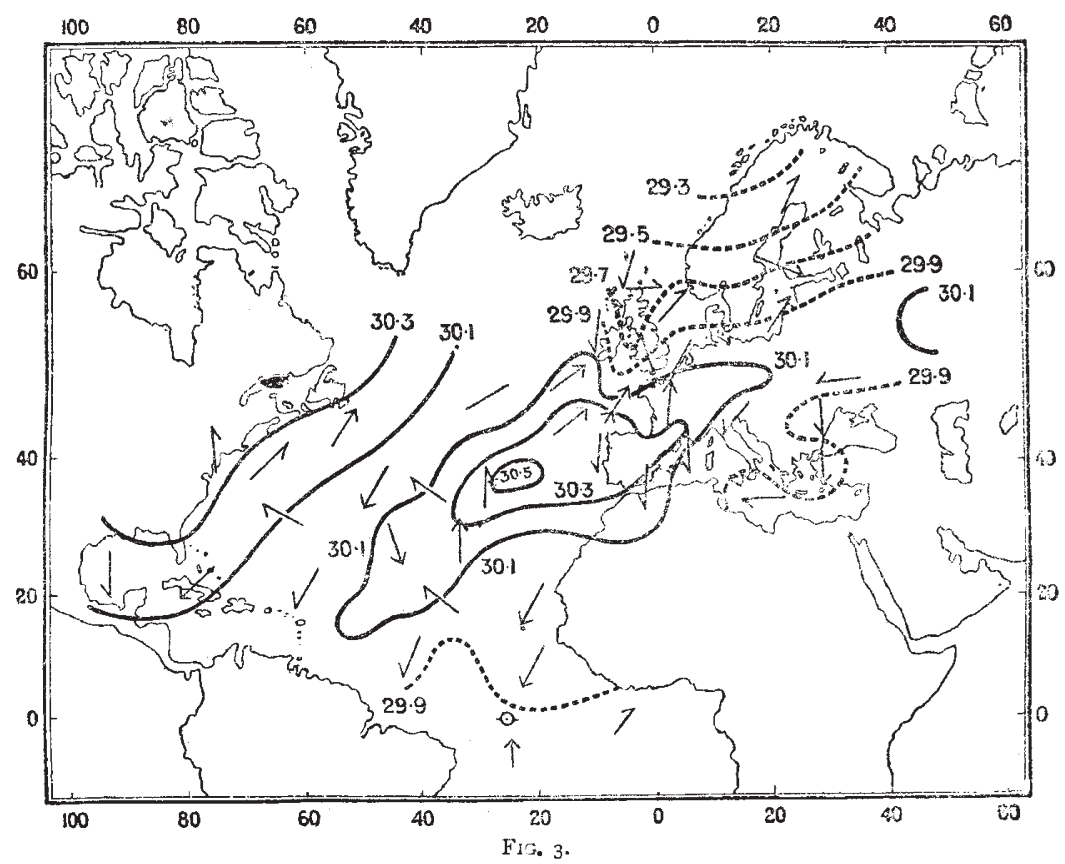

nostics which have been accounted for have been those due to ex - always be exceedingly useful to solitary observers who have omy cessive damp, but by means of isobaric charts many others can a single barometer to depend upon besides these prognostics, is be readily explained. It must not be supposed that the modern for instance on board ship.

methods diminish the value of prognostics, for even in forecast- Though this way of treating prognostics is a great advance on ing weather from synoptic charts they are of great value, and will the older methods, still there remains what may be called a

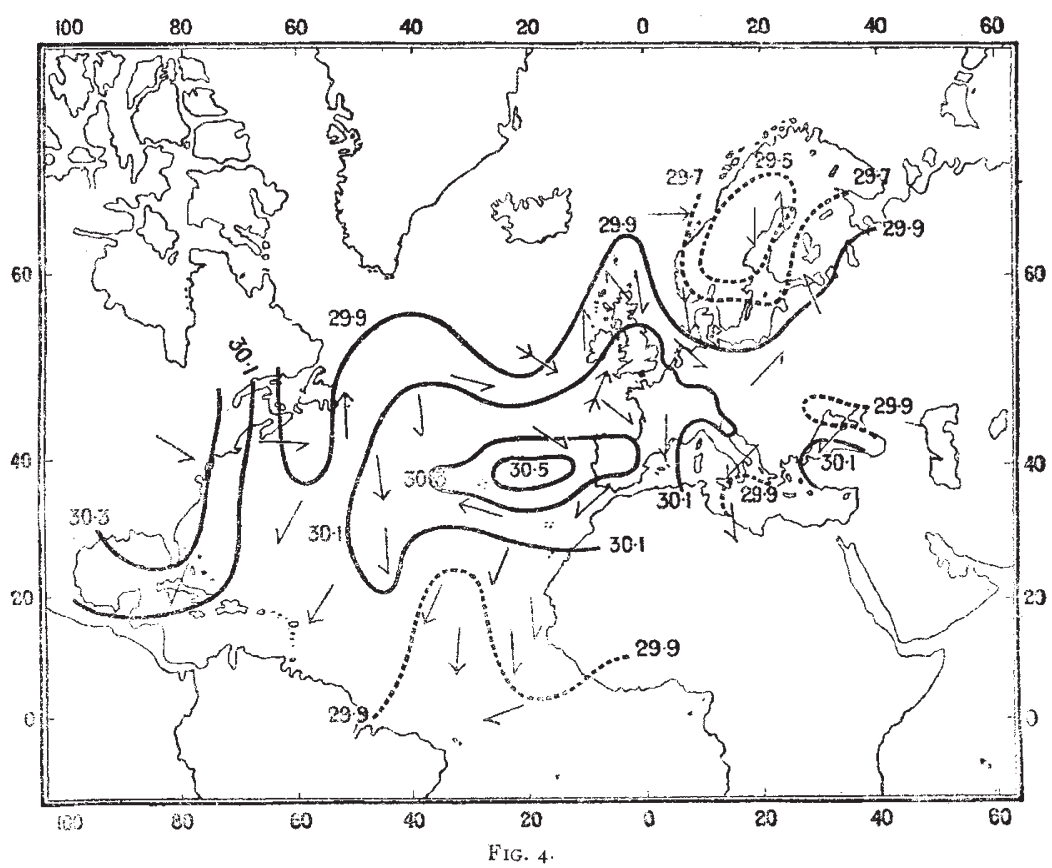

higher line of explanation. There is no doubt that the different there is no doubt that the principal cause of rain in a cyclone is shapes of isobars are the product of different phases of atmo: the condensation of the ascentional current of air round its centre, spheric circulation, just like the eddies and backwaters of a river, while Ley and others have shown that many of the well.known and that the appearance of the weather is the product of the com- forms of clouds are due to the action of upper currents moving in plex vertical and lateral movements thus set up. For instance, a different direction to those on the surface, and with a different 
velocity. Similarly the bright dry weather of an anticyclone is certainly due to the descenting current found round its centre, and so on for every shape of isobars. Any reference to these movements was, however, intentionally omitted by the authors, as these movements are still to a certain extent only partially understood, and it was their de ire to rest the explanations which they gave exclusively on ob ervation without reference to any the rretical considerations.

In a cyclone the broad features of the weather are a patch of rain near the centre, surrounded by a ring of cloud. But if we write down on a diagram, as in Fig. I, the details of weather and kind of cloud in the different portions of the cyclone, we find that many of the best-known prognostics owe their value to the fact that they are characteristic of the front of a cyclone, and that after they have been observed, the rainy portion must pass over the ob:erver before the sky bec smes clear again. Sometimes a cyclone, after crossing a portion of the British Isles, dies out, and then the prog aostics will fail in some districts.

The prognostics of settle 1 fine weather are shown to be characteristic of anticyclones, which are nearly stationary for several days, and even weeks, together.

Though the bulk of British weather is made up of cyclones and anticyclones, there are two other distributions of pressure, marked out by wedge-shaped isobars and straight isobars respec- tively, which are associated with many well-kn ww sayings. The chief interest in these prognostics consists in the contrast which they present to cyclone prognostics, as in many cases they are as iociated with fine and dry weather as opposed to the damp of an approaching cyclone.

In the front of wedge-shaped isobars (which are frequently found batween a retreating and advancing cycl one) the weather is beautifully fine, of the sort of which we should say that it was "too fine to last"; or, if it lasted a whole day, we should cull it a "pet day."

During the day the sun is hot, at night white frost forms. Great visibility, with a blue sky, and unusual refraction, are often observed.

On the west side of the wedge-shaped area, as the new cyclone cones on, the blue sky gradually assumes a dirty appearance, accompanied by a halo, and gathers into cloud, and later on rain begins to fall; while in the southern portion the rain is often preceded by cirrus stripes, either lying with the wind, or sometimes at right angles to it.

"Cirrus at right angles to the wind is a sign of rain."

These are all shown in the diagram (Fig. 2).

Some very interesting rain prognostics are also associated with straight isobars. While those in a cyclose are preceded by an almost ominous calm, and a dirty, murky sky, these are associated

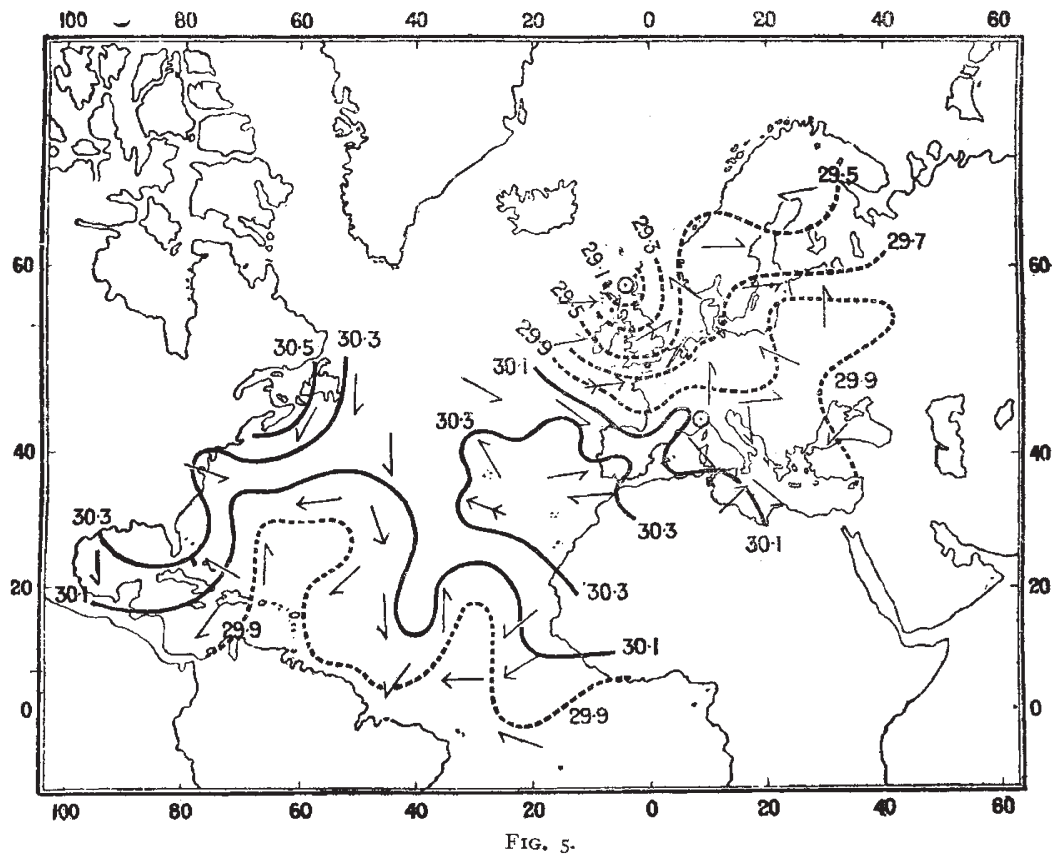

with a hard sky and blustery wind, of which it would be ordinarily remarked that "the wind keeps down the rain," or that, "when the wind falls, it will rain." While also the prognostics which precede cyclone rain hold good for the reason that they are seen in front of the rainy portion, those associated with straight isobars hold good because, though there is little rain actually with them, the area which they cover to-day will probably be covered by a cyclone to-morrow $\rightarrow$ the conditions being favourable for the passage or formation of cyclones.

Altogether, about roo prognostics are associated with these four shapes of isobars.

The use and position of prognostics relative to forecasting from synoptic charts was stated thus :-

Theoretically, when the isobars are well-defined, we ought to be able to write down the prognostics which might be visible, but practically we cannot do so. Besides, there are sometimes cases of isobars which have no well-defined shape, but with which thunderstorm: or heavy showers often occur. These, as is well known, hardly affect the barometer, but are abundantly forewarned by the commonest prognostics, and as the rainfall i usually heavy in the $n$, the failure of the forecast which omits to notice them is very $\mathrm{c}$ ons picuous.

The scope of the paper precluded entering into the compli- cated question of the non-cyclonic rainfalls in this country. It was only stated that the prognostics which precede them are rather those associated with broken weather, such as bright sunrise or heavy clouds banking up without the barometer falling, than the muggy, dirty weather of a cyclone front. The warning they give is also much shorter, rarely more than three or four hours, if so long.

The other paper is an attempt to classify certain types of British weather.

It is familiar to many observers that the weather in this country freyuently occurs in spells of several weeks' duration, during which there is a remarkable persistence of the general type of weather overriding both a considerable fluctuation from day to day, and a considerable local variation from place to place.

For instance, the wind will often back to some point of south with a high temperature, a dull sky and rain, and then veer to some point of west with a cooler air and brighter sky; and after a day or so of fine weather it will back again to the south with bad weather, perhaps this time rising to the intensity of a gale, and subiequently veer towards the west with finer weather, and so on for weeks together.

The changes only vary in intensity and detail, not in general 
character, while the feel of the weather and the look of the sky remain through all of them what are customarily associated with westerly winds.

Similarly the wind will often blow persistently from some point of east, fluctuating between south-east for fouler weather and north-east for finer weather, and back again with many variations for several weeks, during which the predominant features of the weather are always characteristic of east winds. The frequent recurrence of particular types of weather at particular seasons of the year is also a matter of common observation; the north-east winds of March, the cold north winds of the middle of June, and the wet west winds of September are well-known instances.

If we examine a large number of synoptic charts we find that relatively to Europe the general position of the gr sat areas cof high pressure frequently remained constant for a lengthened period. Further examination shows that the constancy of these positions coincides with persistent types of weather similar to those above mentioned, the fluctuation of type being due to the passage of cyclones, while the local variation depends on the position of the cyclone centres and on the innumerable local conditions which modify any general type.

Over the North Atlantic and Europe the distribution of atmospheric pressure presents certain constant features, namely-

I. An equatorial belt of nearly uniform low pressure.

2. A tropical belt of high pressure rising at intervals into great irregular elevations or anticyclones.

3. A temperate and Arctic region of generally low pressure, but in which occasionally areas of high pressure appear for a considerable period.

The equatorial belt constantly covers the Sahara and the Amazon valley, and always narrows over the Atlantic at about $30^{\circ}$ west longitude, where it often does not reach higher than $10^{\circ}$ north latitude. The shape and depth of this area are tolerably constant.

The tropical belt comprises a region of high pressure rising at variable intervals into great anticyclones. Their position is generally variable, with the exception of one, which is always found over the central Atlantic. This anticyclone forms a very important factor of the weather of western Europe, and will be constantly referred to as "the Atlantic anticyclone." Its ex. tension south and west is tolerably constant, while towards north and east it is variable, sometimes rising as far as $60^{\circ}$ north and stretching over Great Britain and continental Europe.

The temperate and Arctic region extends from the tropical high pressure belt to the pole. The pressure, thongh ordinarily low, is perpetually fluctuating by reason of the incessant passage of cyclones; yet occasionally persistent areas of high pressure appear in certain portions of it.

With reference to western Europe there are at least four persistent types of weather-

I. The southerly, in which an anticyclone lies to the east or south-east of Great Britain, while cyclones coming in from the Atlantic either beat up against it or pass towards north-east.

2. The westerly, in which a tropical belt of anticyclones is found to the south of Great Britain, and the cyclones which are formed in the central Atlantic pass towards east or north-east.

3. The northerly, in which the Atlantic anticyclone stretches far to the west and north.west of Great Britain, roughly covering the ocean. In this case cyclones spring up on the north or east side, and either work round the anticyclone to the southeast, or leave it and travel rapidly towards the east.

4. The easterly, in wbich an apparently non-tropical anticyclone (or one disconnected with the tropical high-pressure belt) app:ars in the north-east of Europe, rarely extending beyond the coast-line, while the Atlantic anticyclone is occasionally totally absent from the Bay of Biscay. The cyclones, then, either come in from the Atlantic and pass south-east between the two anticyclones, or else, their progress being impeded, they are arrested or deflected by the north-east anticyclone. Sometimes they are formed to the south of the north-east anticyclone, and advance slowly towards the east, or in very rare instances towards the west.

The details of the southerly and westerly types are given in the paper. Here we can only reproduce the three diagrams of the westerly type, Figs. 3, 4, and 5, in which the general characteristics of the type, just mentioned, are readily seen.

The value of the recognition of type groups is shown in the following ways :-

I. They explain many phenomena of weather, and many popular prognostics.

For instance. besides showing the nature of spells of good, bad, dry weather, \&c., they explain by reason of their per:istence such prognostics as why "grouse coming down into farmyards are a sign of snow." Also why the prognostics, "When a river like the Tweed rises without any rain having fallen," or "Irregular tides are signs of rain," have a significance for the future ; for though both are caused by past bad weather at a distance, yet the persistent type will almost certainly sconer or later bring more bad weather over the place of observation.

Then the recurrence of hot and cold periods, many of them well known, are shown to be due to the recurrence of a similar type of pressure distribution about the same season of the year. Particulars of seventeen such are given, and the manner in which the knowledge of them can be utilised in forecasting is stated thus: that though the forecaster is not justified in stating that any period will occur absolutely, still when about the time of its usual recurrence the synoptic charts show signs of the expected type, then the forecasts for a few days ahead can be issued with greater confidence. For instance, suppose that about November 6-a cold period-the charts begin to show traces of the northerly type, then, but not before, there would be good grounds for saying that a period of cold weather, which usually occurs at this season, has already set in, and may be expected to last for five or six days, the forecaster being thus enabled to issue a much longer forecast than can as a rule be safely attempted.

2. Type groups are of the utmost value in forecasting, for when the existence of the type is fairly recognised then the general features of the weather are at once given, as well as the probable motion of the cyclones which are formed during the continuance of the type. Unfortunately in many cases no certain indications can be given of an approaching change of type.

3. Statistical results can be corrected by their means, for they give a true test of identity of recurrent weather, which no single item, such as heat, cold, rain, \&c., can do.

4. They enable geological questions to be treated, such as the influence of changing distribution of land and sea on climate, in a more satisfactory manner th:n any other method.

The general principles of prognostics and types hold all over the world, but the details in the papers apply to Great Britain only.

RALPH ABERCROMBY

\section{OUR ASTRONOMTCAL COLUMN}

The GREAT COMET OF I882.- It appears quite possible that as the moon draws away from the morning sky towards the end of the present month, this comet may be again observed with our larger instruments. Its distance from the earth has been increasing from soon after perihelion passage in September last, and a maximum takes place at the beginning of September next, when the distance is 5.988 ; the earth then for a time overtakes the comet, and the distance diminishes to 5.709 on December I. The intensity of light, however, is greatest at the end of August, and the comet then rises at a sufficient interval before the sun to render observation feasible. It will at least be of much interest to ascertain if the comet can be reached with our most powerful telescopes. The only comet which has been hitherto observed under similar conditions is the celebrated one of $18 \mathrm{r}$, which, it may be remembered, was observed by Wisniewsky at NeuTscherkask, in August I812.

The following places are deduced from the elliptical element calculated by W. Fabritius of Kiev (Astron. Nach., Nọ. 25I4), from a wider arc of observation than any other orbit yet published :-

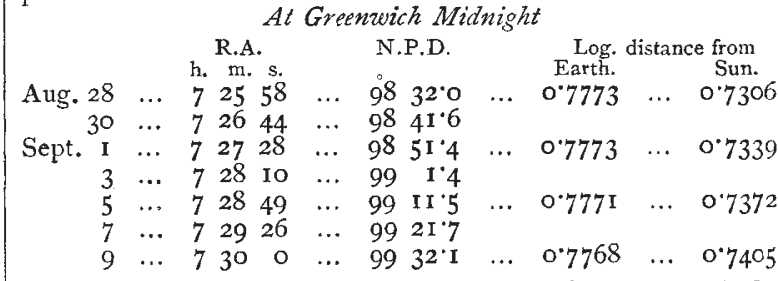

Dr. Julius Schmidt last saw the comet at Athens on April 28; in a letter addressed to NATURE, Mr. A. S. Atkinson of Nelson, N.Z., states that with a 4 -inch refractor he saw it with certainty on May 6. Assuming the theoretical intensity of light on the latter date to be unity, the intensity on August 28 is 0.35 .

The Astronomische Gesellschaft.-The next meeting of this society will be held at Vienna, in the apartments of the Academy of Sciences, from September $14-17$, under the presi- 